\title{
The SPARC-related modular calcium binding protein 2 (SMOC2) gene polymorphism in primary glaucoma: a case-control study
}

This article was published in the following Dove Press journal:

Clinical Ophthalmology

20 March 2017

Number of times this article has been viewed

\author{
Najwa Al-Dabbagh' \\ Hamoud Al-Shahrani' \\ Nourah Al-Dohayan' \\ Md Mustafa ${ }^{2}$ \\ Misbahul Arfin² \\ Abdulrahman K Al-Asmari \\ 'Department of Ophthalmology, \\ ${ }^{2}$ Research Center, Prince Sultan \\ Military Medical City, Riyadh, \\ Saudi Arabia
}

\begin{abstract}
Primary glaucomas are among the most common eye diseases that may potentially result in bilateral blindness. Both genetics and environmental factors are reported to be involved in the etiology of primary glaucomas. Secreted protein acidic and rich in cysteine (SPARC)related modular calcium binding protein 2 (SMOC2) is a matricellular glycoprotein encoded by the SMOC2 gene and known to regulate the expression of extracellular matrix (ECM) proteins and matrix metalloproteinases (MMPs), which play an important role in the pathogenesis of primary glaucomas. The frequencies of alleles and genotypes of SMOC2 variants were examined in 406 Saudi subjects, including primary open angle glaucoma (POAG, $n=140$ ) and primary angle closure glaucoma (PACG, $n=64$ ) patients and 202 matched healthy controls using the polymerase chain reaction-restriction fragment length polymorphism (PCR-RFLP) technique. Genotyping of SMOC2 polymorphism (rs13208776) revealed a significantly higher frequency of the heterozygous genotype GA $(P<0.01)$ and a lower frequency of wild type GG genotype $(P=0.05)$ in glaucoma patients compared to the controls. Upon stratification of the patients on the basis of types of glaucoma, PACG patients had a significantly higher frequency of GA genotype as compared to the controls $(P<0.01)$, whereas there was no significant difference between the POAG patient and control groups in frequencies of SMOC2 alleles and genotypes. Further, there was no significant difference in frequency distribution of alleles and genotypes between male and female patients. This study indicates that the GA genotype of $\operatorname{SMOC2}(\mathrm{G}>\mathrm{A})$ polymorphism is significantly associated with PACG and may be a risk factor. However, further large-scale studies in the Saudi population as well as in other ethnic populations are needed to confirm this association.
\end{abstract}

Keywords: glaucoma, $S M O C 2$, polymorphism, genotyping, genetics, Saudi

\section{Introduction}

Glaucoma is a complex and genetically heterogeneous group of optic neuropathies. Glaucoma affects 70 million people and is the second leading cause of blindness worldwide. ${ }^{1}$ Primary glaucoma is one of the most common eye diseases and is classified as primary open angle glaucoma (POAG) and primary angle closure glaucoma (PACG). PACG is characterized by shallow interior chamber depth and short axial length and is a leading form of glaucoma in the Asian population, ${ }^{2}$ while POAG is characterized by gonioscopically open interior chamber and is the prevalent form of glaucoma in several populations. ${ }^{1,3}$ In glaucoma, the progressive loss of retinal ganglion cells results in abnormal appearance of optic nerve head and chronic painless progression of visual field defects. Elevated intraocular pressure (IOP) is one of the known risk factors for glaucoma. The association of other risk factors like genetic predisposition,
Correspondence: Abdulrahman K Al-Asmari

Research Center, Prince Sultan Military Medical City, PO Box 7897, Riyadh

I I I59, Saudi Arabia

Email abdulrahman.alasmari@gmail.com 
oxidative stress, inflammation, and environmental factors with glaucoma is under intense research.

Recent studies, including those from our laboratory, have indicated that genetic factors, ${ }^{4-7}$ environmental factors, ${ }^{8}$ and gene-environment interaction ${ }^{9}$ affect the etiology of glaucoma. In spite of the advancement and progress in medical science, the exact mechanism and pathogenesis of glaucoma are far from clear, and further studies are required to explain the complex etiology of glaucoma.

Secreted protein acidic and rich in cysteine (SPARC)related modular calcium binding protein 2 (SMOC2) is a matricellular glycoprotein encoded by the SMOC2 gene (ID: 64094) located on chromosome 6q27. Matricellular proteins are known to regulate the expression of several secreted extracellular matrix (ECM) proteins and matrix metalloproteinases (MMPs). ${ }^{10-12}$ Higher levels of MMPs have been reported in glaucomatous eyes as compared to normal eyes. ${ }^{13-15}$

Selection of the SMOC2 gene in the present study was based mainly on its biological role similar to SPARC in signaling ${ }^{16}$ and the fact that it is expressed mainly in the ECM of corneal keratocytes, trabecular meshwork, and ciliary muscles. ${ }^{17,18}$ Moreover, the presence of SPARC in ocular tissue and its role in the development of glaucoma has been suggested by several studies ${ }^{10,19}$ and has also been supported by various experimental studies. ${ }^{20-22}$ A further role of SMOC2 in collagen synthesis has been supported by an earlier study showing positive association of SPARC with the expression of collagen I in PACG patients. ${ }^{10}$

Single nucleotide polymorphism (SNP) rs13208776 is an $\mathrm{A} / \mathrm{G}$ single-nucleotide variation located on chromosome $6 q 27$, within intron 4 of the SMOC2 gene. We hypothesized that SNP rs13208776 might be associated with high levels of MMPs, which implies more ECM degradation and remodeling process in glaucomatous eyes. To the best of our knowledge, no other study has been undertaken to evaluate SMOC2 gene polymorphism in glaucoma patients so far. Therefore, the present study was designed to investigate any possible association of SMOC2 $(\mathrm{G}>\mathrm{A})$ polymorphism with susceptibility to primary glaucomas (POAG and PACG) in the Saudi Arabian population.

\section{Materials and methods}

A total of 406 subjects, including 204 primary glaucoma patients (POAG [n=140] and PACG [n=64]) visiting an ophthalmology clinic and 202 age- and sex-matched healthy controls from the same ethnicity (Saudi) visiting a community health clinic of Prince Sultan Military Medical City (PSMMC), Riyadh, Saudi Arabia, were recruited for this study. All subjects were biologically unrelated Saudi Arabs. This study was approved by the Ethical Committee of PSMMC, Riyadh, and written informed consent was obtained from all study participants before the recruitment. The patient group consisted of 103 males and 101 females with age at diagnosis ranging from 30 to 78 years (mean $\pm \mathrm{SD}=58 \pm 14.4$ ). The control group consisted of an equal number of males and females, ranging from age 25 to 68 years (mean \pm $\mathrm{SD}=55 \pm 11.6)$. None of the healthy controls had evidence of any ocular diseases or autoimmune/autoinflammatory and systemic disorders.

The diagnosis of glaucoma was based on the clinical observations as described in previous studies. ${ }^{4,5}$

Patients with a confirmed diagnosis of PACG or POAG and free from any other systemic and autoimmune diseases were selected for this study, while patients with signs of intracranial disease that would cause optic nerve atrophy in X-ray computerized tomography or magnetic resonance imaging were excluded. Venous blood ( $3 \mathrm{~mL}$ ) was drawn from each subject, brought to the laboratory in an ice box, and stored at $-80^{\circ} \mathrm{C}$ before extraction of DNA.

\section{Genotyping}

For analysis of SMOC2 gene polymorphism, polymerase chain reaction-restriction fragment length polymorphism (PCR-RFLP) technique was used as described elsewhere. ${ }^{23}$ Genomic DNA was extracted from whole blood using the QIAamp DNA mini kit (Qiagen, Venlo, Limburg, the Netherlands). The quality of the DNA was checked on agarose gel and quantitation was done using Nano Drop-2000 (Thermo Fisher Scientific Inc., Waltham, MA, USA).

An amplicon of $485 \mathrm{bp}$ containing the SNP was generated using forward primer: 5'-CTCAGAAATTGGCACCCTCT-3' and reverse primer: 5'-GTCTCCGGTTTAAGGGAGGA-3'. DNA amplification was done in a $25 \mu \mathrm{L}$ reaction mixture consisting of $50 \mathrm{ng}$ of genomic DNA, $10 \mathrm{mM}$ of each primer, and $0.2 \mathrm{mM}$ of dNTPs mixture. Genomic DNA was amplified for 35 cycles. Initial denaturation was done for 3 minutes at $95^{\circ} \mathrm{C}$. Each cycle consisted of $95^{\circ} \mathrm{C}$ for $30 \mathrm{sec}, 59^{\circ} \mathrm{C}$ for $30 \mathrm{sec}$, and $72^{\circ} \mathrm{C}$ for $45 \mathrm{sec}$; PCR products obtained were separated by electrophoresis on $2.5 \%$ agarose gel in Tris-borate-EDTA (TBE) buffer, visualized by ethidium bromide fluorescence. The PCR product was digested with the BsaHI enzyme (New England Biolab, Ipswich, MA, USA) for 3 hours at $37^{\circ} \mathrm{C}$. The restriction fragments were separated by $3 \%$ agarose gel electrophoresis to identify the genotype. Variant allele (A) resulted in $388 \mathrm{bp}$ and $97 \mathrm{bp}$ fragments from one restriction site (one restriction site is lost in mutant allele), and variant allele $\mathrm{G}$ resulted in the digestion of $485 \mathrm{bp}$ amplicon into 
$233 \mathrm{bp}, 165 \mathrm{bp}$, and $97 \mathrm{bp}$ fragments from two restriction sites (homozygous wild type). Heterozygous genotype (GA) has four fragments of 388 bp, 233 bp, 165 bp, and 97 bp.

\section{Statistical analysis}

Frequencies of various alleles and genotypes of SMOC2 polymorphism were compared between patients and controls and analyzed by Fisher's exact test, and the $P$-values $\leq 0.05$ were considered significant. Genetic data were expressed as odd ratio interpreted as relative risk (RR), according to the method of Woolf as outlined by Schallreuter et al. ${ }^{24} \chi^{2}$ test was used to calculate $95 \%$ confidence interval (CI). The RR was calculated only for those alleles and genotypes that were increased or decreased in glaucoma patients as compared to controls. RR indicates the number of times risk of disease is higher in terms of allele/genotype in cases as compared to controls. The RR was calculated for all the subjects using the formula given below:

$$
\mathrm{RR}=\frac{a \times d}{b \times c}
$$

$a=$ number of patients with expression of allele or genotype, $b=$ number of patients without expression of allele or genotype, $c=$ number of controls with expression of allele or genotype, and $d=$ number of controls without expression of allele or genotype.

Etiologic Fraction (EF) indicates the hypothetical genetic component of the disease. The values $0.0-0.99$ are of significance. EF was calculated for positive association only where $\mathrm{RR}>1$ using the following formula: ${ }^{25}$

$$
\mathrm{EF}=\frac{(\mathrm{RR}-1) f}{\mathrm{RR}}, \text { where } f=\frac{a}{a+c}
$$

Preventive Fraction (PF) indicates the hypothetical protective effect of one specific allele/genotype for the disease. PF was calculated for negative association only where $\mathrm{RR}<1$ using the following formula. ${ }^{25}$ Values $<1.0$ indicate the protective effect of the allele/genotype against the manifestation of disease.

$$
\mathrm{PF}=\frac{(1-\mathrm{RR}) f}{\mathrm{RR}(1-f)+f}, \text { where } f=\frac{a}{a+c}
$$

\section{Results}

The results of the genotypes and alleles distribution of SMOC2 polymorphism in primary glaucoma and controls are summarized in Tables $1-5$. The representative gel picture for different genotypes is shown in Figure 1.

The frequency of GA genotype was significantly higher $(P<0.01)$, while the frequency of GG genotype was lower in primary glaucoma patients as compared with controls $(P=0.05)$. The difference in frequencies of genotype AA in the patient and control groups was not statistically significant $(P=0.11)$. Frequency of allele A was found to be higher, while that of allele $\mathrm{G}$ was lower in glaucoma patients than in controls, but the difference was not statistically significant $(P=0.38$, Table 1$)$. Further, no significant difference was found in the distribution of alleles and genotypes of SMOC2 polymorphisms between male and female patients (Table 2).

Stratification of genotyping results into POAG and PACG groups and comparison of the frequency distribution of genotypes and alleles of SMOC2 polymorphism showed significant differences between the two groups. The GA genotype was significantly higher $(P=0.04)$, while the $\mathrm{GG}$ genotype was significantly lower $(P=0.01)$ in the PACG as compared to the POAG patients. The frequency of allele A was significantly higher in the PACG patients, whereas the frequency of allele $\mathrm{G}$ was higher in the POAG patients (Table 3, Figure 2).

The comparison of frequencies of alleles and genotypes of SMOC2 polymorphism between the POAG and the control group is shown in Table 4 . There was no significant difference in the allele or genotype distribution between the POAG patients and the controls. On the other hand,

Table I Allele and genotypic distribution of the SMOC2 (G>A) polymorphism in PG patients and controls

\begin{tabular}{lllllll}
\hline Genotype/allele & $\begin{array}{l}\text { Controls }(\mathbf{n}=\mathbf{2 0 2}) \\
\text { N (Frequency \%) }\end{array}$ & $\begin{array}{l}\text { PG }(\mathbf{n}=\mathbf{2 0 4}) \\
\mathbf{N} \text { (Frequency \%) }\end{array}$ & P-value & RR & EF $/$ PF & $\begin{array}{l}\text { Odds ratio } \\
(\mathbf{9 5 \%} \text { Cl) }\end{array}$ \\
\hline GG & $95(47.29)$ & $76(37.25)$ & $0.05^{\mathrm{b}}$ & 0.66 & 0.23 & Reference \\
GA & $90(44.55)$ & $119(58.33)$ & $<0.01^{\mathrm{b}}$ & 1.74 & $0.24^{\mathrm{a}}$ & $1.65(1.09-2.48)$ \\
AA & $17(8.4 \mathrm{I})$ & $09(4.40)$ & 0.11 & 0.50 & 0.25 & $0.62(0.27-1.56)$ \\
G & $280(69.30)$ & $271(66.42)$ & 0.38 & 0.86 & 0.14 & $1.14(0.85-1.53)$ \\
A & $124(30.69)$ & $137(33.57)$ & 0.38 & 1.14 & $0.06^{\mathrm{a}}$ & \\
\hline
\end{tabular}

Notes: aData for EF; bstatistically significant using Fisher's exact test.

Abbreviations: PG, primary glaucoma; EF, etiological fraction; PF, preventive fraction; N, number of subjects; RR, relative risk. 
Table 2 Allele and genotype distribution of the SMOC2 (G>A) polymorphism in male and female primary glaucoma patients

\begin{tabular}{lllllll}
\hline Genotype/allele & $\begin{array}{l}\text { Male }(\mathbf{n}=\mathbf{I 0 3}) \\
\text { N (Frequency } \%)\end{array}$ & $\begin{array}{l}\text { Female }(\mathbf{n}=\mathbf{I 0 I}) \\
\mathbf{N} \text { (Frequency \%) }\end{array}$ & P-value & RR & EFa/PF & $\begin{array}{l}\text { Odds ratio } \\
(\mathbf{9 5 \%} \text { CI) }\end{array}$ \\
\hline GG & $4 I(39.80)$ & $36(35.64)$ & 0.56 & 0.83 & 0.77 & Reference \\
GA & $56(54.36)$ & $6 I(60.39)$ & 0.39 & 1.2 & $0.11^{\mathrm{a}}$ & $1.24(0.69-2.20)$ \\
AA & $06(5.82)$ & $04(3.92)$ & 0.75 & 0.66 & 0.05 & $0.75(0.19-2.90)$ \\
G & $138(67)$ & $133(65.84)$ & 0.83 & 0.94 & 0.02 & $1.05(0.69-1.58)$ \\
A & $68(33)$ & $69(34.16)$ & 0.83 & 1.05 & $0.02^{\mathrm{a}}$ & \\
\hline
\end{tabular}

Note: ${ }^{a}$ Data for EF.

Abbreviations: $\mathrm{N}$, number of subjects; RR, relative risk; $\mathrm{EF}$, etiological fraction; PF, preventive fraction.

Table 3 Allele and genotype distribution of the SMOC2 (G>A) polymorphism in POAG and PACG patients

\begin{tabular}{lllll}
\hline Genotype/allele & POAG (n=| 40) & PACG (n=64) & P-value & $\begin{array}{l}\text { Odds ratio } \\
(\mathbf{9 5} \% \mathbf{C I})\end{array}$ \\
\hline GG & N (Frequency \%) & N (Frequency \%) & & Reference \\
GA & $65(46.42)$ & $18(28.21)$ & $0.0 I^{\mathrm{a}}$ & $2.16(1.13-4.13)$ \\
AA & $70(50)$ & $42(65.62)$ & $0.04^{\mathrm{a}}$ & $2.88(0.70-11.88)$ \\
G & $05(3.5)$ & $04(6.25)$ & 0.46 & $1.60(1.03-2.48)$ \\
A & $200(71.42)$ & $78(60.93)$ & $0.03^{\mathrm{a}}$ & $0.03^{\mathrm{a}}$ \\
\hline
\end{tabular}

Note: aStatistically significant using Fisher's exact test.

Abbreviations: POAG, primary open angle glaucoma; PACG, primary angle closure glaucoma; N, number of subjects; RR, relative risk.

Table 4 Comparison of allele and genotype distribution of the SMOC2 (G>A) polymorphism between POAG patients and controls

\begin{tabular}{lllllll}
\hline Genotype/allele & $\begin{array}{l}\text { Controls }(\mathbf{n}=\mathbf{2 0 2}) \\
\text { N (Frequency \%) }\end{array}$ & $\begin{array}{l}\text { POAG }(\mathbf{n}=\mathbf{I 4 0 )} \\
\text { N (Frequency \%) }\end{array}$ & P-value & RR & EFa/PF & $\begin{array}{l}\text { Odds ratio } \\
(\mathbf{9 5} \% \mathbf{C I})\end{array}$ \\
\hline GG & $95(47.29)$ & $65(46.42)$ & 0.99 & 0.97 & 0.01 & Reference \\
GA & $90(44.55)$ & $70(50)$ & 0.34 & 1.24 & $0.08^{\mathrm{a}}$ & $1.13(0.72-1.77)$ \\
AA & $17(8.41)$ & $05(3.5)$ & 0.07 & 0.40 & 0.25 & $0.43(0.15-1.22)$ \\
G & $280(69.30)$ & $200(71.42)$ & 0.67 & 1.10 & $0.10^{\mathrm{a}}$ & $0.90(0.64-1.26)$ \\
A & $124(30.69)$ & $80(28.57)$ & 0.67 & 0.90 & 0.03 & \\
\hline
\end{tabular}

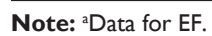

Abbreviations: POAG, primary open angle glaucoma; N, number of subjects; RR, relative risk; EF, etiological fraction; PF, preventive fraction.

Table 5 Comparison of allele and genotype distribution of the SMOC2 (G>A) polymorphism between PACG patients and controls

\begin{tabular}{lllllll}
\hline Genotype/allele & $\begin{array}{l}\text { Controls (n=202) } \\
\text { N (Frequency \%) }\end{array}$ & $\begin{array}{l}\text { PACG (n=64) } \\
\text { N (Frequency \%) }\end{array}$ & P-value & RR & EF $/$ PF & $\begin{array}{l}\text { Odds ratio } \\
(\mathbf{9 5} \% \text { CI) }\end{array}$ \\
\hline GG & $95(47.29)$ & $18(28.2 \mathrm{I})$ & $<0.0 I^{\mathrm{b}}$ & 0.44 & 0.15 & Reference \\
GA & $90(44.55)$ & $42(65.62)$ & $<0.0 I^{\mathrm{b}}$ & 2.37 & $0.18^{\mathrm{a}}$ & $2.46(1.32-4.59)$ \\
AA & $17(8.4 I)$ & $04(6.25)$ & 0.79 & 0.72 & 0.06 & $1.24(0.37-4.12)$ \\
G & $280(69.30)$ & $78(60.93)$ & 0.08 & 0.69 & 0.08 & $1.44(0.95-2.18)$ \\
A & $124(30.69)$ & $50(39.06)$ & 0.08 & 1.44 & $0.08^{\mathrm{a}}$ & \\
\hline
\end{tabular}

Notes: aData for EF; 'statistically significant using Fisher's exact test.

Abbreviations: PACG, primary angle closure glaucoma; N, number of subjects; RR, relative risk; EF, etiological fraction; PF, preventive fraction. 


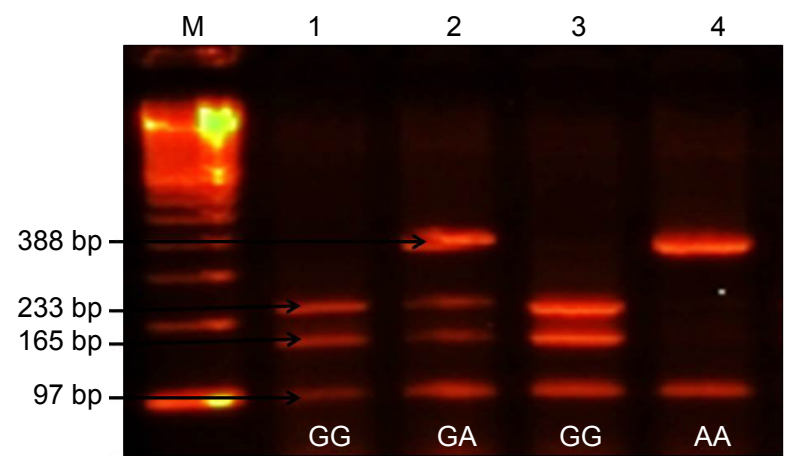

Figure I Shows different genotypes of SMOC2 polymorphism.

Notes: Lane M: 100 bp DNA marker, Lane I and 3: homozygous (GG) wild type (97 bp, 165 bp, and 233 bp), Lane 2: heterozygous (GA) genotype (388 bp, 233 bp, 165 bp, and $97 \mathrm{bp}$ ), Lane 4: mutant (AA) genotype (97 bp and 388 bp).

comparison of alleles and genotypes in PACG with controls revealed significant differences in genotype frequencies in the two groups. The genotype GG was significantly lower $(P<0.01)$ and the genotype GA was significantly higher in the PACG $(P<0.01)$ as compared to the control group. However, no significant difference was observed in the allelic distribution between the PACG patients and the controls (Table 5).

\section{Discussion}

The significantly higher frequencies of genotype GA of the SMOC2 polymorphism in the primary glaucoma patients as compared to the controls indicated that the genotype GA is associated with susceptibility to primary glaucoma ( $R R=1.74, E F=0.24)$. The lower frequency of genotype GG in the patients as compared to the controls suggested that genotype GG might be protective to primary glaucoma ( $\mathrm{RR}=0.66, \mathrm{PF}=0.23$ ) in Saudi patients (Table 1). Our results indicated that there was no significant association of

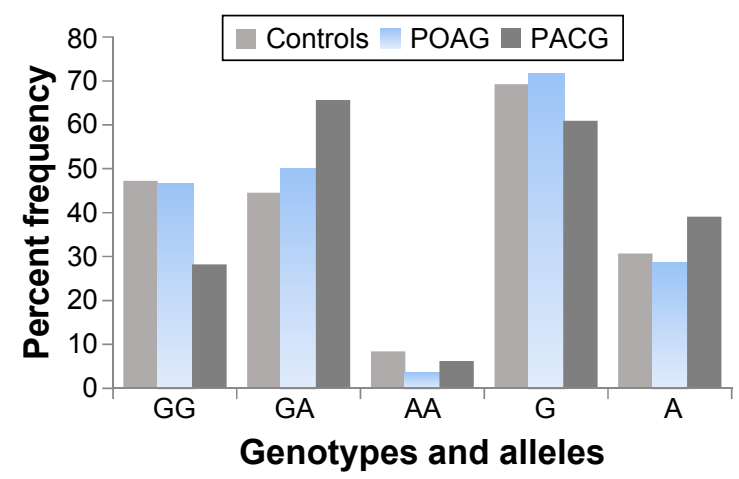

Figure 2 Shows the frequencies of various genotypes and alleles in the controls and POAG and PACG patients.

Abbreviations: POAG, primary open angle glaucoma; PACG, primary angle closure glaucoma.
SMOC2 polymorphism with sex of the primary glaucoma patients (Table 2).

Comparison of the distribution of genotypes and alleles in POAG and PACG showed significant differences between the two groups (Table 3, Figure 2). Stratification of genotyping results into PACG and POAG and comparing with controls revealed that $S M O C 2$ polymorphism is significantly associated with the susceptibility to PACG but not to POAG in the Saudi population, as the frequency distribution of genotypes and alleles was not different in the POAG and control groups (Table 4). On the contrary, the genotype GA was significantly higher and genotype GG was significantly lower in the PACG patients as compared to the controls (Table 5). The present findings indicated that genotype GG of SMOC2 might play a protective role in the etiology of PACG.

Our findings also suggested that carriers of the GA genotype of SMOC2 polymorphism are more vulnerable to $\mathrm{PACG}$ as compared to POAG possibly owing to the association of the SMOC2 gene with collagen I and III synthesis. An overall increase in collagen, particularly collagen I, has been reported in the iris of stroma. ${ }^{26}$ Collagen I synthesis has been reported 2.0-fold and 5.2-fold higher in PACG cases as compared to POAG and nonglaucomatous cases, respectively. ${ }^{10}$ It has also been suggested that the increase in content and structural organization of collagen I leads to an increase in the iris rigidity and tensile strength, and, ultimately, changes in the biomechanical properties of iris and development of PACG. ${ }^{27,28}$ The role of SMOC2 in collagen synthesis is also supported by the earlier study showing positive association of SPARC with the expression of collagen I in the PACG patients. ${ }^{10}$ Recently, the SPARC null mouse has been reported to have a lower IOP than the wild type mouse probably owing to decreased outflow resistance. The heterozygous state of SPARC in mice has also been associated with an intermediate phenotype suggestive of a dose-dependent effect of SPARC. ${ }^{29}$

SMOC2 gene polymorphism has also been associated with autoimmune diseases such as vitiligo and autoimmune thyroid disease, ${ }^{23,30,31}$ pulmonary function, ${ }^{32}$ and cancer. ${ }^{33}$ A strong genome-wide association of SMOC2 polymorphism with generalized vitiligo has been reported for the high-risk allele in the Romanian closed population. ${ }^{30}$ An association of SMOC2 polymorphism has also been reported with vitiligo and autoimmune thyroid disease in the Jordanian Arab population. ${ }^{23,31}$ On the other hand, no association of SMOC2 polymorphism was reported with susceptibility to age-related macular degeneration in Jordanian Arabs. ${ }^{34}$ However, the mechanism by which the SMOC2 gene polymorphism 
may affect susceptibility/development of these diseases is still unknown, although its role in cell cycle regulation, ${ }^{16}$ metastasis, ${ }^{35}$ and angiogenesis has been suggested. ${ }^{33}$

Another possible mechanism for SMOC2 gene polymorphism in the susceptibility to primary glaucoma may be based on the role of multiple domain glycoprotein. Glycoprotein encoded by SMOC2 contains two thyroglobulin type-I domains, two EF-hand calcium-binding domains, a follistatin-like domain, and a putative signal peptide. ${ }^{18,36}$ The thymoglobulin domains bind and act as inhibitors to different proteases, such as serine and cysteine proteases. ${ }^{37,38}$ The follistatin-like domains, including the Kazal-type protease inhibitor domain, are usually indicative of serine protease inhibitors. SMOC2 with multiple domains has the potential to act as protease inhibitors. ${ }^{39}$ The protease/ antiprotease imbalance has also been reported as a key factor in abnormal matrix accumulation leading to potential involvement in the pathogenesis of glaucoma. ${ }^{40}$ It can be suggested that polymorphism in the SMOC2 gene may be associated with low levels of protease inhibitor subsequently resulting in high MMPs. This is in line with a recent report indicating higher levels of MMP-2 in PACG and POAG patients as compared to controls. ${ }^{40}$

MMPs can modulate the aqueous humor flow through their ability to remodel trabecular meshwork in ECM, which leads to constant outflow resistance, resulting in increased IOP. ${ }^{14}$ Being a matricellular protein, SMOC-2 may simulate SPARC in regulating cell-matrix interactions, cell adhesion, ECM deposition, angiogenesis, and signaling molecules such as cytokines and matrix proteases, as reported for SPARC. ${ }^{11,12,41}$ It is possible that improper regulation of the SMOC2 gene and subsequent ECM modification may play a crucial role in IOP regulation and, possibly, pathophysiology of glaucoma, as suggested for SPARC by Chatterjee et al. ${ }^{12}$

To the best of our knowledge, this is the first study on the SMOC2 gene polymorphism and susceptibility to glaucoma. Identification of genetic susceptibility variants will lead to a better understanding of the role of variable risk factors in the etiology of glaucoma. Recently, the role of matricellular proteins in glaucoma has emerged as an important tool for therapeutic target as some of these proteins have an association with the pathophysiology of the trabecular meshwork and lamina cribrosa regions, as recently suggested by Wallace et al. ${ }^{42}$ Therefore, such studies on matricellular protein synthesizing genes will be of great value and may help in developing strategies for therapeutic intervention. The Saudi population, being a closed and isolated society with a high rate of consanguinity (inbreeding), may represent a valuable resource for studying the genetics of primary glaucoma, and further association studies involving various genes will be helpful in clarifying the complex etiology of primary glaucoma.

\section{Conclusion}

The present study suggests an association of genotype GA of SMOC2 polymorphism with susceptibility to PACG in the Saudi test population. Further studies with larger sample sizes from different ethnicities will strengthen the observation of the present study.

\section{Acknowledgment}

The authors thank S Sadaf Rizvi and Mohammad K Al-Asmari for their help with laboratory work. No external grants or other support were received for conducting this study.

\section{Author contributions}

All authors contributed toward data analysis, drafting and critically revising the paper and agree to be accountable for all aspects of the work.

\section{Disclosure}

The authors report no conflicts of interests in this work.

\section{References}

1. Quigley HA, Broman AT. The number of people with glaucoma worldwide in 2010 and 2020. Br J Ophthalmol. 2006;90(3):262-267.

2. Quigley HA, Congdon NG, Friedman DS. Glaucoma in China (and worldwide): changes in established thinking will decrease preventable blindness. Br J Ophthalmol. 2001;85(11):1271-1272.

3. He M, Foster PJ, Ge J, et al. Prevalence and clinical characteristics of glaucoma in adult Chinese: a population-based study in Liwan District, Guangzhou. Invest Ophthalmol Vis Sci. 2006;47(7):2782-2788.

4. Al-Dabbagh NM, Al-Dohayan N, Arfin M, Tariq M. Apolipoprotein E polymorphisms and primary glaucoma in Saudis. Mol Vis. 2009;15: 912-919.

5. Al-Dabbagh NM, Al-Dohayan N, Al-Asmari AK, Arfin M, Tariq M. Association of TNF- $\alpha$ and TNF- $\beta$ gene polymorphisms with primary open angle and primary angle closure glaucoma. In: Kofranova M, Kubena T, editors. The Mystery of Glaucoma. Rijeka, Croatia: InTech Publisher; 2011:229-256.

6. Guo H, Li M, Wang Z, Liu Q, Wu X. Association of MYOC and APOE promoter polymorphisms and primary open-angle glaucoma: a metaanalysis. Int J Clin Exp Med. 2015;8(2):2052-2064.

7. Wu M, Zhu XY, Ye J. Associations of polymorphisms of LOXL1 gene with primary open-angle glaucoma: a meta-analysis based on 5,293 subjects. Mol Vis. 2015;21:165-172.

8. Renard JP, Rouland JF, Bron A, et al. Nutritional, lifestyle and environmental factors in ocular hypertension and primary open-angle glaucoma: an exploratory case-control study. Acta Ophthalmol. 2013;91(6): 505-513.

9. Wiggs JL. The cell and molecular biology of complex forms of glaucoma: updates on genetic, environmental, and epigenetic risk factors. Invest Ophthalmol Vis Sci. 2012;53(5):2467-2469.

10. Chua J, Seet LF, Jiang Y, et al. Increased SPARC expression in primary angle closure glaucoma iris. Mol Vis. 2008;14:1886-1892.

11. Scavelli K, Chatterjee A, Rhee DJ. Secreted Protein Acidic and Rich in Cysteine in Ocular Tissue. J Ocul Pharmacol Ther. 2015;31(7):396-405. 
12. Chatterjee A, Villarreal G, Rhee DJ. Matricellular proteins in the trabecular meshwork: review and update. J Ocul Pharmacol Ther. 2014; 30(6):447-463.

13. Schlötzer-Schrehardt U, Lommatzsch J, Küchle M, Konstas AG, Naumann GO. Matrix metalloproteinases and their inhibitors in aqueous humor of patients with pseudoexfoliation syndrome/glaucoma and primary open-angle glaucoma. Invest Ophthalmol Vis Sci. 2003; 44(3):1117-1125.

14. De Groef L, Van Hove I, Dekeyster E, Stalmans I, Moons L. MMPs in the trabecular meshwork: promising targets for future glaucoma therapies? Invest Ophthalmol Vis Sci. 2013;54(12):7756-7763.

15. Fountoulakis N, Labiris G, Aristeidou A, et al. Tissue inhibitor of metalloproteinase 4 in aqueous humor of patients with primary open angle glaucoma, pseudoexfoliation syndrome and pseudoexfoliative glaucoma and its role in proteolysis imbalance. BMC Ophthalmol. 2013;13:69.

16. Liu P, Lu J, Cardoso WV, Vaziri C. The SPARC-related factor SMOC-2 promotes growth factor-induced cyclin D1 expression and DNA synthesis via integrin-linked kinase. Mol Biol Cell. 2008;19(1):248-261.

17. Maier S, Paulsson M, Hartmann U. The widely expressed extracellular matrix protein SMOC-2 promotes keratinocyte attachment and migration. Exp Cell Res. 2008;314(13):2477-2487.

18. Vannahme C, Gösling S, Paulsson M, Maurer P, Hartmann U. Characterization of SMOC-2, a modular extracellular calcium-binding protein. Biochem J. 2003;373:805-814.

19. Comes N, Borrás T. Individual molecular response to elevated intraocular pressure in perfused postmortem human eyes. Physiol Genomics. 2009;38(2):205-225.

20. Taneda S, Pippin JW, Sage EH, et al. Melioration of diabetic nephropathy in SPARC-null mice. J Am Soc Nephrol. 2003;14(4):968-980.

21. Bradshaw AD, Puolakkainen P, Dasgupta J, Davidson JM, Wight TN, Sage EH. SPARC-null mice display abnormalities in the dermis characterized by decreased collagen fibril diameter and reduced tensile strength. J Invest Dermatol. 2003;120(6):949-955.

22. Bradshaw AD, Sage EH. SPARC, a matricellular protein that functions in cellular differentiation and tissue response to injury. J Clin Invest. 2001;107(9):1049-1054.

23. Alkhateeb A, Al-Dain Marzouka N, Qarqaz F. SMOC2 gene variant and the risk of vitiligo in Jordanian Arabs. Eur J Dermatol. 2010;20(6): 701-704.

24. Schallreuter KU, Levenig C, Kühnl P, Löliger C, Hohl-Tehari M, Berger J. Histocompatibility antigens in vitiligo: Hamburg study on 102 patients from northern Germany. Dermatology. 1993;187(3):186-192.

25. Svejgaard A, Platz P, Ryder LP. HLA and disease 1982 a survey. Immunol Rev. 1983;70:193-218.

26. Konstas AG, Marshall GE, Lee WR. Immunocytochemical localisation of collagens (I-V) in the human iris. Graefes Arch Clin Exp Ophthalmol. 1990;228(2):180-186.

27. Brekken RA, Sage EH. SPARC, a matricellular protein: at the crossroads of cell-matrix communication. Matrix Biol. 2001;19(8):816-827.
28. He M, Lu Y, Liu X, Ye T, Foster PJ. Histologic changes of the iris in the development of angle closure in Chinese eyes. J Glaucoma. 2008;17(5): 386-392.

29. Haddadin RI, Oh DJ, Kang MH, et al. SPARC-null mice exhibit lower intraocular pressures. Invest Ophthalmol Vis Sci. 2009;50(8):3771-3777.

30. Birlea SA, Gowan K, Fain PR, Spritz RA. Genome-wide association study of generalized vitiligo in an isolated European founder population identifies SMOC2, in close proximity to IDDM8. J Invest Dermatol. 2010;130(3):798-803.

31. Alkhateeb A, Marzouka NA, Tashtoush R. Variants in PTPN22 and SMOC2 genes and the risk of thyroid disease in the Jordanian Arab population. Endocrine. 2013;44(3):702-709.

32. Wilk JB, Herbert A, Shoemaker CM, Gottlieb DJ, Karamohamed S. Secreted modular calcium-binding protein 2 haplotypes are associated with pulmonary function. Am J Respir Crit Care Med. 2007;175(6): 554-560.

33. Rocnik EF, Liu P, Sato K, Walsh K, Vaziri C. The novel SPARC family member SMOC-2 potentiates angiogenic growth factor activity. $J$ Biol Chem. 2006;281(32):22855-22864

34. Alkhateeb AM, Ali AJ, Marzouka NA, Al-Khatib SQ. Lack of association between SMOC2 polymorphism and age-related macular degeneration in Jordanian Arabs. Saudi Med J. 2012;33(9):1018-1020.

35. Król M, Polańska J, Pawłowski KM, et al. Transcriptomic signature of cell lines isolated from canine mammary adenocarcinoma metastases to lungs. J Appl Genet. 2010;51(1):37-50.

36. Nishimoto S, Hamajima Y, Toda Y, Toyoda H, Kitamura K, Komurasaki T. Identification of a novel smooth muscle associated protein, smap2, upregulated during neointima formation in a rat carotid endarterectomy model. Biochim Biophys Acta. 2002;1576(1-2):225-230.

37. Lenarcic B, Ritonja A, Strukelj B, Turk B, Turk V. Equistatin, a new inhibitor of cysteine proteinases from Actinia equina, is structurally related to thyroglobulin type-1 domain. J Biol Chem. 1997;272(21): 13899-13903.

38. Galesa K, Pain R, Jongsma MA, Turk V, Lenarcic B. Structural characterization of thyroglobulin type-1 domains of equistatin. FEBS Lett. 2003;539(1-3):120-124.

39. Williamson MP, Marion D, Wüthrich K. Secondary structure in the solution conformation of the proteinase inhibitor IIA from bull seminal plasma by nuclear magnetic resonance. J Mol Biol. 1984;173(3):341-359.

40. Nga AD, Yap SL, Samsudin A, Abdul-Rahman PS, Hashim OH, Mimiwati Z. Matrix metalloproteinases and tissue inhibitors of metalloproteinases in the aqueous humour of patients with primary angle closure glaucoma - a quantitative study. BMC Ophthalmol. 2014;14:33.

41. Bornstein P, Sage EH. Matricellular proteins: extracellular modulators of cell function. Curr Opin Cell Biol. 2002;14(5):608-616.

42. Wallace DM, Murphy-Ullrich JE, Downs JC, O'Brien CJ. The role of matricellular proteins in glaucoma. Matrix Biol. 2014;37:174-182.
Clinical Ophthalmology

\section{Publish your work in this journal}

Clinical Ophthalmology is an international, peer-reviewed journa covering all subspecialties within ophthalmology. Key topics include: Optometry; Visual science; Pharmacology and drug therapy in eye diseases; Basic Sciences; Primary and Secondary eye care; Patient Safety and Quality of Care Improvements. This journal is indexed on Submit your manuscript here: http://www.dovepress.com/clinical-ophthalmology-journa

\section{Dovepress}

PubMed Central and CAS, and is the official journal of The Society of Clinical Ophthalmology (SCO). The manuscript management system is completely online and includes a very quick and fair peer-review system, which is all easy to use. Visit http://www.dovepress.com/ testimonials.php to read real quotes from published authors. 